\title{
Using smartphone app collected data to explore the link between mechanization and intra-household allocation of time in Zambia
}

\author{
Thomas Daum ${ }^{1} \cdot$ Filippo Capezzone ${ }^{2} \cdot$ Regina Birner $^{1}$
}

Accepted: 18 September 2020 / Published online: 13 October 2020

(c) The Author(s) 2020

\begin{abstract}
Digital tools may help to study socioeconomic aspects of agricultural development that are difficult to measure such as the effects of new policies and technologies on the intra-household allocation of time. As farm technologies target different crops and tasks, they can affect the time-use of men, women, boys, and girls differently. Development strategies that overlook such effects can have negative consequences for vulnerable household members. In this paper, the time-use patterns associated with different levels of agricultural mechanization during land preparation in smallholder farming households in Zambia were investigated. A novel data collection method was used: a pictorial smartphone application that allows real-time recording of time-use, which eliminates recall bias. Existing studies analyzing the intra-household allocation of resources often focus on adult males and females. This study paid particular attention to boys and girls as well as adults. The study addressed seasonal variations. Compositional data analysis was used to account for the co-dependence and sum constraint of time-use data. The study suggests a strong gender differentiation for land preparation activities among mechanized households; for households using manual labor, such differentiation was not found. There is some evidence that the surplus time associated with mechanization is used for off-farm and domestic work. The study cannot confirm concerns about negative second-round effects: mechanized land preparation is not associated with a higher workload for women and children during weeding and harvesting/processing. The study provides a proof-of-concept that smartphone applications can be used to collect socioeconomic data that are difficult to measure but of high relevance.
\end{abstract}

Keywords Agricultural mechanization · Agricultural transformation $\cdot$ Labor division $\cdot$ Gender $\cdot$ Time-use $\cdot$ Africa

$\begin{array}{ll}\text { Abbreviations } \\ \text { ADP } & \text { Animal draught power } \\ \text { Alr } & \text { Additive log-ratios } \\ \text { CoD } & \text { Compositional data } \\ \text { CoDA } & \text { Compositional data analysis }\end{array}$

Thomas Daum

thomas.daum@uni-hohenheim.de

Filippo Capezzone

filippo.capezzone@gmx.de

Regina Birner

regina.birner@uni-hohenheim.de

1 Division of Social and Institutional Change in Agricultural Development, Hans-Ruthenberg-Institute of Agricultural Science in the Tropics, University of Hohenheim, Wollgrasweg 43, 70599 Stuttgart, Germany

2 Division of Biostatistics, Institute of Crop Science, University of Hohenheim, Fruwirthstraße 23, 70599 Stuttgart, Germany

$\begin{array}{ll}\text { G } & \text { Gender } \\ \text { M } & \text { Mechanization } \\ \text { NERICA } & \text { New rice for Africa } \\ \text { Tuc } & \text { Time-use categories }\end{array}$

\section{Introduction}

The need to study the gender implications of agricultural development is widely acknowledged (Ball 2020; Doss 2001; Garcia and Wanner 2017; Theis et al. 2018; Quisumbing et al. 2014). This includes, but is not limited to, monitoring the intra-household time-use effects when promoting new technologies and implementing policies in developing countries (Wodon and Blackden 2006; Bryceson 2019; Doss 2013). Since smallholder farming is often characterized by a division of labor, new technologies and policies can affect adult men and women as well as boys and girls differently (Wodon and Blackden 2006; Doss 2001; Quisumbing et al. 
1996). Development strategies that overlook such dynamics can fail or have negative consequences for vulnerable household members (Agarwal 1981; Bergman-Lodin et al. 2012; Kumar 1995; Doss 2001; Quisumbing et al. 1996). For example, conservation agriculture can increase the workload for women because of a higher weed pressure (Beuchelt and Badstue 2013; Farnworth et al. 2016) and NERICA can prevent children from going to school because of an exacerbated need for bird scaring (Bergman-Lodin et al. 2012). Time-use changes affecting women may have negative consequences on nutrition and childcare (Johnston et al. 2018; Lamidi 2019) and can alter women's ability to manage their time effectively, and relax.

While there is a consensus on the importance of studying the gender effects related to the adoption of new technologies, empirical research can be constrained by a lack of good data. This is because household surveys may fail to adequately capture socioeconomic aspects that have to be recalled by respondents (Arthi et al. 2018; Bell et al. 2019; Carletto et al. 2015a, b; Fraval et al. 2019; Seymour et al. 2020). The collection of time-use data exemplifies the challenges faced by researchers. Typically used methods such as post-harvest questionnaires and 24-h recall questions are prone to recall bias; in contrast, time-use diaries are more accurate but require literacy and familiarity with clock-based concepts of time; and direct observations are expensive and associated with observer bias (Arthi et al. 2018; Daum et al. 2019).

In the digital age, times are changing, however, and various researchers have explored new ways to collect data that are more accurate from farmers in developing countries. For example, researchers have used GPS devices to measure plot sizes (Carletto et al. 2015b), fitness-trackers to capture energy expenditure (Zanello et al. 2017), and satellites to assess yields (Lobell et al. 2020). Collecting digital data on less tangible, non-physical socioeconomic aspects has been neglected, however. This study explores whether a digital tool can also be used to collect such types of data, focusing on time-use; and to investigate whether such data can help to study the gender effects of new technologies and policies. For this, a smartphone application called Timetracker was developed that allows the self-recording of data by respondents. The Timetracker is based on visual tools to ensure that illiterate respondents and children can record data, and allows real-time recording of data to reduce recall bias (Daum et al. 2019).

Using the collected data, this study explores the complex time-use patterns associated with different levels of technology adoption using agricultural mechanization, ${ }^{1}$ which has

\footnotetext{
1 Agricultural mechanization is an umbrella term and its technologies can be targeted towards different crops and farm operations.
}

potentially large labor effects, as a case study. Mechanization is unfolding rapidly in Asia (Wang et al. 2016) and is increasingly promoted in Africa (Daum and Birner 2020, 2017; Benin 2015; Diao et al. 2014). Some studies have looked at the gender aspects of agricultural mechanization (Baudron et al. 2019; Eerdewijk and Danielsen 2015; Fischer et al. 2018). Eerdewijk and Danielsen (2015), for example, find that women have limited voice over mechanization adoption decisions, which makes it more likely that households invest in and adopt technologies that save men's time (see also Doss 2001). However, we could find no study that has examined how agricultural mechanization affects the intra-household time allocation in African countries, notwithstanding some anecdotal evidence.

The relationship between mechanization and time-use within households is likely to be complex because of the division of labor by gender and age, second-round effects (mechanizing one farm step can affect non-mechanized steps), substitution effects to alternative activities, complimentary input use, and intra-household decision-making processes. Thus, as noted by Eerdewijk and Danielsen (2015, p. 54) "neither direct nor indirect benefits, hence, can be assumed, but have to be monitored".

To address this complexity, detailed time-use data from different household members in households with different types of mechanization during an entire farming season is needed. Thus, data was collected from 62 households associated with different levels of agricultural mechanization; relying on either tractors, draft animals or human power for their farm operation. Data was collected from both men and women as well as children. This is a unique contribution, as existing studies analyzing labor use and resource allocation in farm households mainly focus on adults (Doss 2013). This is although $60 \%$ of all child labor is in agriculture, affecting around 100 million girls and boys (ILO 2020). Data was collected during one farming season.

Analyzing time-use data is associated with some specific challenges. Studying the time spent on different activities in isolation of each other can be misleading since total time-use always sums up to $24 \mathrm{~h}$ and, as time-use is intrinsically codependent, an increase in time spent on one activity reduces the time available for other activities (Chastin et al. 2015; Gupta et al. 2018). Standard statistical techniques can thus result in spurious correlations (Pearson 1897). To address these challenges, compositional data analysis is used in this paper (Aitchinson 1982; Bacon-Shone 2011). Another challenge when studying the relationship between mechanization and time-use is establishing causality. Ultimately, this would require panel data and a larger sample, preferably a randomized control trial. However, concerning the use of tractors, conducting a randomized control trial is more costly compared to other interventions (e.g., mosquito net programs). Therefore, it seems sensible to conduct an 
Fig. 1 Conceptual Framework. Source: Authors. The dashed boxes refer to intermediate steps. The greyed boxes refer to the allocation of resources (time, income, and food/nutrients)

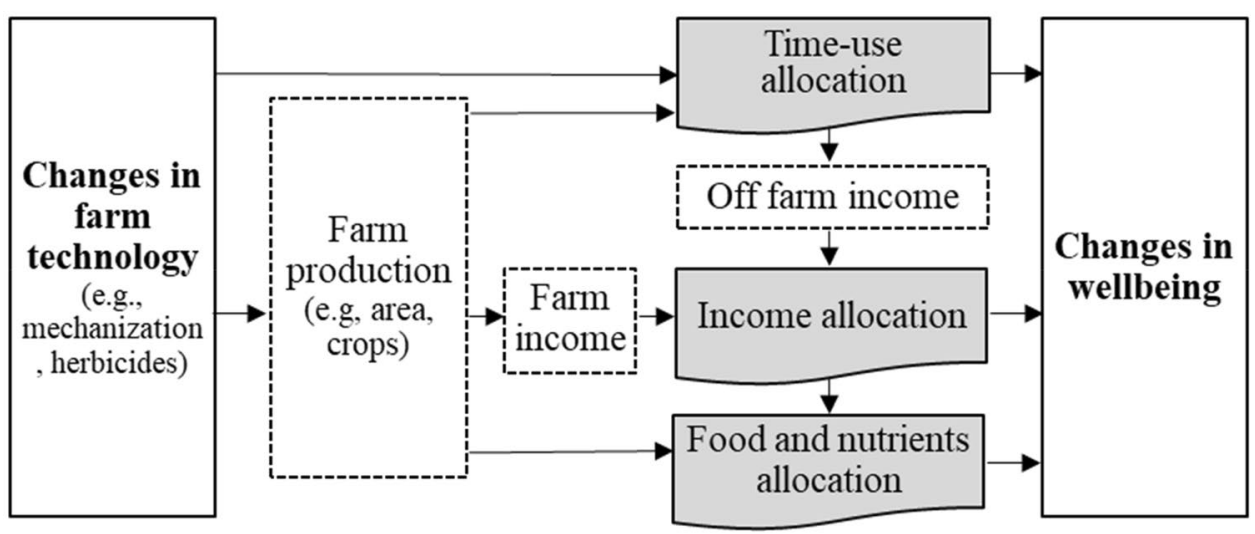

explorative study before conducting any large-scale randomized control trial, which could apply the Timetracker application.

The study should be understood as a proof-of-concept case study. In particular, the paper has two major objectives: (1) providing a proof-of-concept that using digital tools can help to collect highly disaggregated time-use data from different household members, including children; (2) exploring how time-use differs by levels of mechanization, paying particular attention to gender, child labor, and seasonality.

\section{Conceptual framework and research hypotheses}

Farm technologies such as mechanization can affect the well-being of household members through various pathways, in particular, time-use, income, and food and nutritionrelated pathways (see Fig. 1). This paper focuses on time-use (Fig. 1). Generally, it is important to note that all changes in Fig. 1 depend on intra-household decision-making processes, which are influenced by bargaining power and social norms (Doss 2013). ${ }^{2}$

Figure 1 shows that new technologies can have direct effects on time-use (and physical activity, the degree of burden related to time-use). In the case of mechanization, activities, and crops that are mechanized are expected to be associated with a lower workload. Yet, as men and women as well as boys and girls may carry out different activities and can be responsible for different crops (Arora 2015;

\footnotetext{
${ }^{2}$ Intra-household decision making determines the current resource allocation within the household, the farm technology to be adopted, the access to it, and the control over its potential profits, who may be disadvantaged, and how potential time-use changes can be re-negotiated. For example, an increase in women's burden may occur when women do not have the bargaining power to reject more labor-intense technologies or to demand a re-allocation of activities (Fisher et al. 2000).
}

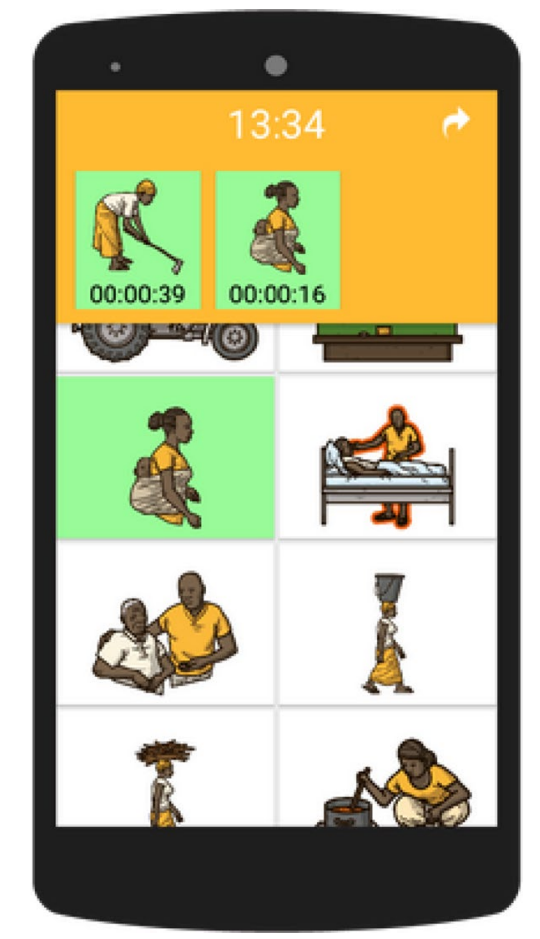

Fig. 2 The Timetracker

Wodon and Blackden 2006; Quisumbing et al. 1996), different household members may experience different direct effects related to mechanization. ${ }^{3}$ Moreover, new technologies can also change workloads through indirect or secondround effects-via changes in farm production, such as in the types of crops grown and area cultivated. This paper will test four different research hypotheses related to the time-use pathway:

H1 Land preparation is predominantly a male activity. ${ }^{3}$ Little is known about the different roles of children in farm house-
holds. 
A
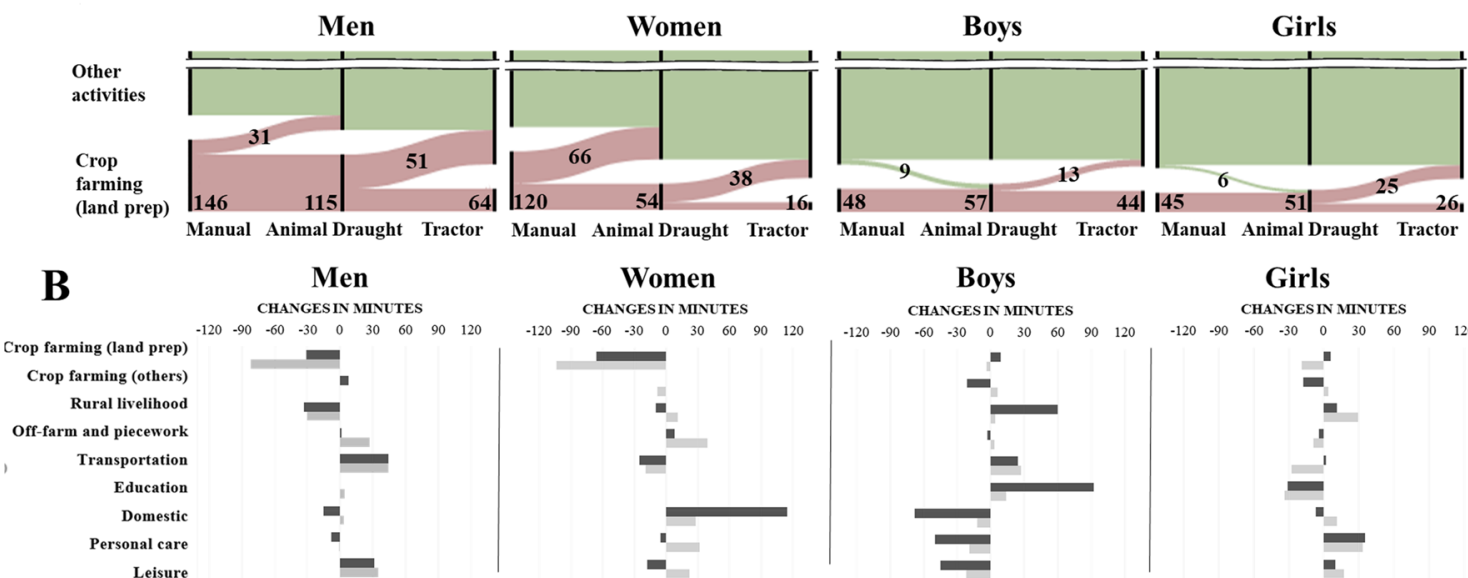

Women

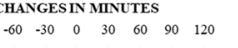
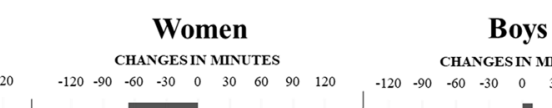

Boys

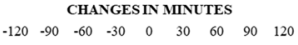

$\begin{array}{lllll}-60 & -30 & 0 & 30 & 60\end{array}$

Girls
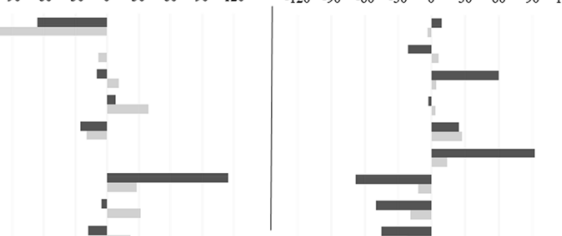

CHANGES IN MINUTES
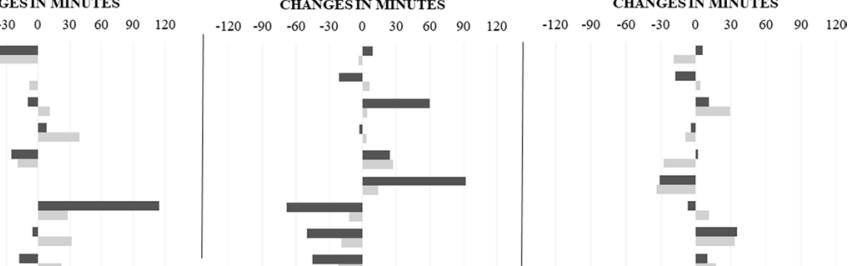

-

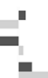

-

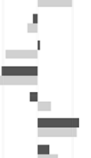

Animal Draught - Manual

Tractor - Manual

Fig. 3 Time-use during the land preparation period. a Alluvial diagram of time-use differences (in minutes) during the land preparation period for men, women, boys, and girls in households with different power sources for land preparation. The node height for the time-use activity "other activities" is broken for illustration purposes. b Comparison of time-use (in minutes) during the land preparation period between animal draught and manual as well as tractor and manual power using households for men, women, boys, and girls
$\mathrm{H} 2$ The use of mechanization during land preparation is associated with lower workloads for men as compared to women.

H3 The surplus time associated with mechanization is used differently by gender.

H4 On mechanized farms, females spend more time on weeding and harvesting/processing compared to females on non-mechanized farms.

$H 1$ and $H 2$ were formulated given evidence suggesting that men may experience the most direct benefits from the mechanization of land preparation. In an analysis of four African Eerdewijk and Danielsen (2015) find that women have limited voice over mechanization adoption decisions. Thus, as indicated by Evers and Walters (2001), households may target time-reducing inputs such as mechanization towards "male" crops and activities such as land preparation (Alesina et al. 2013; Baanante et al. 1999), which tends to be a major labor bottleneck (Binswanger 1986). Also, households may target mechanization on crops that are easy to mechanize — and often controlled by men — such as maize (Kansanga et al. 2019). However, as gender roles vary across space and time (Lambrecht et al. 2018) and as assumptions on gender roles have to be constantly questioned (PalaciosLopez et al. 2017), it cannot simply be assumed that land preparation activities are predominantly male activities and that men benefit most from the mechanization of land preparation.
$H 3$ was formulated based on evidence that the effects of new technologies on the well-being of household members depend on how other time-use activities are affected and for which activities the freed up time will be used (e.g. leisure time, time for off-farm work, and education. Gender roles and intrahousehold decision-making processes are likely to shape how the surplus time associated with mechanization is used. Such gender roles and decision-making processes are in turn are influenced by bargaining power and social norms (Doss 2013).

$\mathrm{H} 4$ was formulated based on the concern that the mechanization of land preparation can lead to the expansion of the land area cultivated by a household. This has been observed by Takeshima et al. (2013) in Northern Nigeria, Adu-Baffour et al. (2019) in Zambia, and Kirui (2019) in eleven African countries. Area expansion may then increase the need for weeding and harvesting and the time spent for collecting firewood once forests are cleared, which are tasks often performed by women and children (Alesina et al. 2013; Arora 2015; Baanante et al. 1999; Wodon and Blackden 2006; Doss 2001). This land expansion related change pathway was not analyzed by any prior study but was observed on an anecdotal basis in India by Mukhopadhyay (1984). He found that the mechanization of plowing (which was a male activity) led to a higher workload for women since they were then "dealing with bigger crops over a larger acreage without mechanization of any of the operations they control" (p.58). However, second-round effects may also benefit women. Using qualitative methods, Baudron et al. (2019) found that mechanized land preparation reduced the need for weeding, a labor-intensive and often female task as referenced above. Moreover, second-round effects depend 
on the use of complementary inputs such as herbicides and hired labor. Thus, it cannot simply be assumed that mechanized land preparation is associated with a higher workload for women during subsequent farming steps.

\section{Study site, data collection method, and sampling}

\section{Study site}

The study was conducted in the Eastern Province, which is one of Zambia's most important smallholder agricultural regions. The average size of land cultivated is 2.3 hectares and mainly maize, cotton, sunflower, groundnuts, and tobacco are grown (IAPRI 2016). Farming is rain-fed and constrained by an extensive dry season. The emergence of medium-scale farmers (Jayne et al. 2016) has led to more farmers owning tractors and providing services to neighboring farmers, but the access to mechanizations remains low: $1 \%$ use their own or hired tractors for land preparation and 57\% use their own or hired animal traction on a least one plot (IAPRI 2016).

\section{Data collection methods and sampling}

As outlined above, time-use is difficult to measure, especially in developing countries. To address this challenge, a smartphone application called Timetracker was used, which is based on visual tools and allows real-time recording of time-use (see Fig. 2; Daum et al. 2018 and 2019). To start recording an activity, respondents click the respective activity from a list of 88 visualized time-use categories. To end the recording of an activity, respondents click on the same icon again. This way of recording time use is an important feature of the app, as it enables continuous tracking of all activities that a household member carries out during the day (Daum et al. 2018). As shown by Daum et al. (2019) the Timetracker improves data quality as compared to conventional recall-based data collection. The Timetracker can, with a careful introduction, be used by very old, very young, and uneducated people as well as respondents without prior exposure to phones and low literacy (Daum et al. 2019). Data quality was assured by random crosschecks, which also allowed for the correction of mistakes. Generally, respondents have been found to enter data very carefully (Daum et al. 2019). ${ }^{4}$ The app allows one to record up to three activities at a time but the focus here is on primary activities as mechanization is expected to most directly affect these activities. However, future studies may compare secondary

\footnotetext{
${ }^{4}$ For a more detailed discussion on the strengths, weaknesses, prerequisites, potentials as well as costs associated with the method see also Daum et al. (2018).
}

activities of men and women across the three types of mechanized and non-mechanized households.

The Timetracker was developed in a participatory process with farm households in the study area (Daum et al. 2018). Special attention was paid to make the app as easy to use as possible. For example, the size of icons and the clicking duration was adjusted based on user feedback. The activities to be included were identified jointly with respondents to ensure that all rural activities pursued in the study area were covered. While some illustrations refer to one specific activity, e.g. applying pesticides using a knapsack sprayer, others refer to bundles of activities, e.g., land preparation, which comprises hoeing as well as removing brush from the fields, among others. While some activity bundles were not easy to illustrate, it was emphasized during the introductory training that the respective illustrations refer to a set of related activities. All illustrations were tested and icons that could not be easily understood were revised. Illustrations depict men and women depending on who was considered more likely to do the respective activity during the participatory app development process. During the introductory training, it was emphasized that this was only for illustration and that, for example, men can click on icons that show women doing activities and that women can click on icons that show men carrying out activities. The same applies to boys and girls. Future studies may use gender-disaggregated illustration sets for men, women, boys, and girls.

The Timetracker was used to collect data from 62 households: 20 used manual labor, 20 used animal power, and 22 used mechanical traction for land preparation. These three groups will be abbreviated as "manual", "animal draught" and "tractor" households respectively henceforth. Based on the nationally representative Rural Agricultural Livelihood Survey, households were selected using a two-stage random sampling procedure. First, four communities were sampled based on the criteria that in each community at least five households used manual labor, animal traction, and tractors for land preparation, respectively. Second, five manual-, five animal draught-, and five to six tractor-households were randomly selected, wherein each household, at least one adult male, one adult female, and one child were present. If not enough households could be identified based on these criteria, additional households were randomly added from lists of the District Agriculture and Cooperatives Offices. In each household, the household head, the spouse, and the oldest child used the Timetracker. In total, 62 household heads, 62 spouses, and 62 children ( 32 boys and 30 girls) used the Timetracker. The boys were on average 16.15 years old (ranging from 11 to 23 years-with a standard deviation of 3.48). The girls were on average 14.9 years old (ranging from 7 to 21 years - with a standard deviation of 3.45).

The three household members recorded data for three days-during which they continuously carried a smartphone 
Table 1 Sample characteristics

\begin{tabular}{|c|c|c|c|c|c|c|}
\hline \multirow[t]{2}{*}{ Variable } & \multirow[t]{2}{*}{ Manual (I) } & \multirow[t]{2}{*}{ Animal draught (II) } & \multirow[t]{2}{*}{ Tractor (III) } & \multicolumn{3}{|c|}{ Intergroup comparison } \\
\hline & & & & I vs II & I vs III & II vs III \\
\hline \multicolumn{7}{|l|}{ Household characteristics } \\
\hline Household size & $6.6(1.6)$ & $7.8(2.3)$ & $6.7(2.1)$ & NS & NS & NS \\
\hline Gender head male (\%) & $95 \%(0.2)$ & $100 \%(0)$ & $95 \%(0.4)$ & NS & NS & NS \\
\hline Age & $49.7(17.0)$ & $45.1(11.2)$ & $47.3(13.8)$ & NS & NS & NS \\
\hline Education level head (0-18) & $6.8(3.2)$ & $8.5(3.5)$ & $10.5(4.2)$ & NS & $* * *$ & NS \\
\hline \multicolumn{7}{|l|}{ Agronomic characteristics } \\
\hline Land cultivated (ha) & $2.3(1.1)$ & $4.8(3.9)$ & $8.4(5.9)$ & NS & $* * *$ & $* *$ \\
\hline Land owned (ha) & $2.5(1.8)$ & $5.9(6.6)$ & $19.8(30.9)$ & NS & $* * *$ & $* *$ \\
\hline Crop diversity & $3.1(1.1)$ & $3.7(1.1)$ & $3.5(1.0)$ & NS & NS & NS \\
\hline Frequency of animal draught weeding & $0.32(0.4)$ & $0.69(0.5)$ & $0.51(0.4)$ & $* *$ & NS & NS \\
\hline Maize yield (tons/ha) & $1.91(1.6)$ & $2.63(1.6)$ & $3.55(1.9)$ & NS & $* * *$ & NS \\
\hline Fertilizer per ha cultivated $(\mathrm{kg})$ & $110(135)$ & $190(148)$ & $216(206)$ & NS & NS & NS \\
\hline Pesticide per ha cultivated (1) & $1.5(4.6)$ & $8.8(14.8)$ & $5.4(11.5)$ & NS & NS & NS \\
\hline Tropical livestock unit & $0.8(1.0)$ & $7.4(7.9)$ & $6.4(8.0)$ & $* * *$ & $* *$ & NS \\
\hline \multicolumn{7}{|l|}{ Hired labor (hours per cultivated ha) } \\
\hline Land preparation & $4(12)$ & $7(25)$ & $4(10)$ & NS & NS & NS \\
\hline Weeding & $5(24)$ & $14(49)$ & $21(47)$ & NS & NS & NS \\
\hline Harvesting & $9(39)$ & $8(25)$ & $17(35)$ & NS & NS & NS \\
\hline \multicolumn{7}{|l|}{ Socio-economic characteristics } \\
\hline Log income & $7.8(1.6)$ & $9(1.2)$ & $10.3(1.0)$ & $* *$ & $* * *$ & $* * *$ \\
\hline Share off-farm income (\%) & $35(58)$ & $17(31)$ & $33(31)$ & NS & NS & NS \\
\hline Month food shortage & $2.4(0.4)$ & $1.5(0.4)$ & $1.2(0.4)$ & NS & $*$ & NS \\
\hline Distance to nearest market $(\mathrm{km})$ & $6.7(5.2)$ & $6.6(7.0)$ & $4.4(7.0)$ & NS & NS & NS \\
\hline Sample size & 20 & 20 & 22 & & & \\
\hline
\end{tabular}

Standard deviation in brackets. Differences between means are based on Tukey post hoc tests and shown with *, **, and ***, indicating significance of mean differences at the $10 \%, 5 \%$, and $1 \%$ level, respectively

NS not significant

Tropical Livestock Unit with the following weights: cattle $=0.7$, sheep $=0.1$, goats $=0.1$, pigs $=0.2$, chicken $=0.01$

to record activities - at five different points of the 2016/2017 cropping season. This resulted in 2790 data days. Since the smartphone app was used in rotation in four different communities, data was collected on 60 different days, covering between 50 and $75 \%$ of the growing season that lasts 80 to 120 days, ${ }^{5}$ thereby also capturing planting and harvesting date variations of different crops. This paper focuses on the land preparation, weeding, and harvesting/processing season.

At the end of the season, a household survey was conducted.Table 1 provides descriptive statistics about the selected households. It is important to keep in mind the relatively small sample size when looking at the statistical analysis of the differences. It is also important to note some households applied elements of conservation farming, but none practiced a comprehensive system of conservation farming, which includes minimum soil tillage, crop rotation,

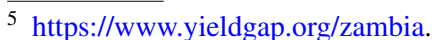

and permanent soil cover. Some households practiced potholing, ${ }^{6}$ but only in kitchen gardens. Most of the mechanized households mostly used disc plows for land preparation, only some used rippers. None of the households used techniques for weed suppression, such as mulching.

Also, six focus group discussions were conducted (three with men and three with women). Visual tools were used to facilitate discussion. For example, respondents were asked to judge activities according to the perceived work toil and enjoyableness. For this, a large sheet of paper with two crossing axes indicating work toil (from hard work to no work) and enjoyableness (from enjoyable to not enjoyable) was used. Respondents were given stickers with different activities that were placed within the framework once a consensus was reached.

\footnotetext{
6 A conservation farming practice were small holes are dug into the field, into which seeds and compost, manure, inorganic fertilizer, lime and are placed. The soil outside of the potholes is left undisturbed (see also https://www.bakerinstitute.org/media/files/page/4f1762b0/ pothole_card_final_english.pdf).
} 
Table 2 Aggregation of time-use activities to overall groups

\begin{tabular}{|c|c|c|}
\hline & Group & Sub activities \\
\hline 1 & Crop farming & \\
\hline 1.1 & Land Preparation & $\begin{array}{l}\text { Land clearing, hoeing, plowing, harrowing, dibbling, potholing, ripping, ridging, raking, building bunds, } \\
\text { removing brash from the fields, among others (all with different power sources) }\end{array}$ \\
\hline 1.2 & Weeding & Weeding by hand or using draught animals, knapsack sprayers, boom sprayers, and pest and disease control \\
\hline 1.3 & Harvesting/processing & $\begin{array}{l}\text { Harvesting, bundling, drying, storing, bagging, shelling, grinding, pounding, milling, winnowing, among } \\
\text { others (all with different power sources) }\end{array}$ \\
\hline 2 & Crop farming (others) & $\begin{array}{l}\text { Planting, applying fertilizer, applying manure, guarding of crops, watering as well as the activities that are } \\
\text { not specific to the respective season (for example weeding and harvesting/processing activities during } \\
\text { land preparation season) }\end{array}$ \\
\hline 3 & Rural livelihood activities & $\begin{array}{l}\text { Beverage preparation, marketing, animal husbandry, hunting, fishing, gathering food and grasses, charcoal } \\
\text { making, maintaining/repairing, farm administration, vegetable garden, construction (household and com- } \\
\text { munity), meeting, cooking (community), among others }\end{array}$ \\
\hline 4 & Off-farm and seasonal labor & Off-farm activities and the above-mentioned farm activities as hired labor \\
\hline 5 & Transportation & $\begin{array}{l}\text { Walking, motorbike, bicycle, animal cart, car/van, bus, tractor (all of which can be loaded or unloaded), } \\
\text { among others }\end{array}$ \\
\hline 6 & Education & \\
\hline 7 & Domestic & $\begin{array}{l}\text { Care of children, sick and old, fetching water, collecting firewood, cooking (household), cleaning, washing } \\
\text { pots and clothes, buying groceries, among others }\end{array}$ \\
\hline 8 & Leisure & Resting, media, religion, chatting, sports, dancing, making music, among others \\
\hline 9 & Personal care & Sleeping, being sick, eating, drinking, personal hygiene, among others \\
\hline
\end{tabular}

\section{Statistical analysis}

The data collected always has positive numbers and sums up to $1440 \mathrm{~min}(24 \mathrm{~h})$ per day. Time spend on different activities is co-dependent: an increase in time spent on one activity reduces the time available for other activities. Such a data structure is known as compositional data $(\mathrm{CoD})$ and requires special attention due to two features: sum constraint and correlation (Aitchinson 1982; Bacon-Shone 2011). A simple series of univariate analyses, where each time-use category is analyzed separately is incapable of accounting for these features. A multivariate analysis, where all categories are analyzed simultaneously, can account for correlation but not for the sum constraint. This can be done by fitting multivariate models to log-transformed ratios of the categories of a composition, so-called log-ratios (BaconShone 2011). Such an approach has been coined compositional data analysis (CoDA) and yields higher accuracy than univariate analysis (Chastin et al. 2015; Gupta et al. 2018).

For this, the values of time spent on single categories underwent an additive log-ratio transformation, where each category is divided by a reference category and the resulting ratios were transformed by taking the natural logarithm (Bacon-Shone 2011). A set of $K=9$ categories was constructed, which resulted in $k=K-1$, i.e. $k=8 \log$-ratios. Table 2 shows the aggregated categories that are based on, in total, 88 activities. The category 'personal care' was used as a reference category. Aitchison (1982) showed that conclusions about relationships of compositions are independent of which category is chosen as reference.

A complication was that some activities were not done by every participant, resulting in zero values, thereby preventing a log-ratio transformation. Following Martín-Fernandez et al. (2003), multiplicative replacement—a method recommended for rounded zeros-was used and zeros were replaced by a small amount of one minute, which constitutes half of the lowest amount of time-use recorded.

A multivariate model was used to study the dependence of additive log-ratios (alr) of time consumption on mechanization and gender. As the sampling was stratified by communities with three different members of each household sampled, the multivariate model for analysis was extended to account for the possible correlations of observations within communities and households. The following multivariate linear mixed model was fitted to the alr-transformed data:

$$
\left(\begin{array}{c}
\log \left(\frac{y_{1 j i m l}}{y_{9 j \mathrm{jm} l}}\right) \\
\vdots \\
\log \left(\frac{y_{8 j \mathrm{jm} l}}{y_{9 i j \mathrm{ml}}}\right)
\end{array}\right)=\left(\begin{array}{c}
\mu_{1} \\
\vdots \\
\mu_{8}
\end{array}\right)+\left(\begin{array}{c}
c_{1 i} \\
\vdots \\
c_{8 i}
\end{array}\right)+\left(\begin{array}{c}
\tau_{1 j} \\
\vdots \\
\tau_{8 j}
\end{array}\right)+\left(\begin{array}{c}
\gamma_{1 l} \\
\vdots \\
\gamma_{8 l}
\end{array}\right)+\left(\begin{array}{c}
(\tau \gamma)_{1 j l} \\
\vdots \\
(\tau \gamma)_{8 j l}
\end{array}\right)+\left(\begin{array}{c}
h_{1 i j m} \\
\vdots \\
h_{8 i j m}
\end{array}\right)+\left(\begin{array}{c}
e_{1 i j m l} \\
\vdots \\
e_{8 i j m l}
\end{array}\right),
$$


where the response vector contains the log-transformed ratios of time of 8 time-use categories divided by the reference category. Each time-use category of each household member with gender $l$ of each household $m$ with mechanization level $j$ from community $i$ underwent this transformation. $\mu_{1}$ to $\mu_{8}$ are the fixed effects of time-use categories (tuc) 1 to $8, c_{1 i}$ to $c_{8 i}$ are the random tuc-specific effects of the $i$-th community, $\tau_{1 j}$ to $\tau_{8 j}$ are the tuc-specific fixed effects of the $j$-th mechanization type with the levels 'manual, 'animal draught', and 'tractor'. $\gamma_{1 l}$ to $\gamma_{1 l}$ are the tuc-specific fixed effects of the $l$-th gender with levels: 'female adult', 'male adult', 'girl' and 'boy'. $(\tau \gamma)_{1 j l}$ to $(\tau \gamma)_{8 j l}$ are the tuc-specific interaction terms of gender and mechanization type. $h_{1 i j m}$ to $h_{8 i j m}$ are the tuc-specific random household effects and $e_{1 i j m l}$ to $e_{8 i j m l}$ are the residual error terms. ${ }^{7}$ The primary regression (1) includes no socio-economic characteristics of households but such characteristics will be controlled for when focusing on the major variables of interest, as further explained below. Individual covariance parameters were estimated for all pairs of tucs, resulting in the following variance-covariance structure for communities:

$\left(\begin{array}{c}c_{1 i} \\ \vdots \\ c_{8 i}\end{array}\right) \sim \operatorname{MVN}\left[\left(\begin{array}{c}0 \\ \vdots \\ 0\end{array}\right),\left(\begin{array}{ccc}\sigma_{c 1}^{2} & \cdots & \sigma_{c 1,8}^{2} \\ \vdots & \ddots & \vdots \\ \sigma_{c 8,1}^{2} & \cdots & \sigma_{c 8}^{2}\end{array}\right)\right]$,

for households

$\left(\begin{array}{c}h_{1 i j m} \\ \vdots \\ h_{8 i j m}\end{array}\right) \sim M V N\left[\left(\begin{array}{c}0 \\ \vdots \\ 0\end{array}\right),\left(\begin{array}{ccc}\sigma_{h 1}^{2} & \cdots & \sigma_{h 1,8}^{2} \\ \vdots & \ddots & \vdots \\ \sigma_{h 8,1}^{2} & \cdots & \sigma_{h 8}^{2}\end{array}\right)\right]$,

and for residual errors:

$\left(\begin{array}{c}e_{1 i j m l} \\ \vdots \\ e_{8 i j m l}\end{array}\right) \sim M V N\left[\left(\begin{array}{c}0 \\ \vdots \\ 0\end{array}\right),\left(\begin{array}{ccc}\sigma_{e 1}^{2} & \cdots & \sigma_{e 1,8}^{2} \\ \vdots & \ddots & \vdots \\ \sigma_{e 8,1}^{2} & \cdots & \sigma_{e 8}^{2}\end{array}\right)\right]$,

resulting in a total of 108 variance-covariance parameters to estimate. Model (1) was fitted to the data of the three seasons separately.

Model parameters were estimated using the HPMIXED procedure of SAS (Version 9.4). Variance components were estimated by the method of restricted maximum likelihood (REML) and subsequently transferred to the MIXED procedure, which was used for inferences on fixed effects. Model assumptions of a normal distribution of residuals and homogeneity of variance were graphically assessed as recommend by Kozak and Piepho (2018). Fixed effects were studied by

\footnotetext{
7 Time-use-category-specific random effects for community, household and residual error were assumed to have a multivariate normal distribution with mean zero and tuc-specific variances.
}

partial Wald-type F-tests. The most appropriate method of Kenward and Roger (1997) to approximate the denominator degrees of freedom was relinquished because of disproportionately high computing time and the 'between-withinmethod' was used instead (Schluchter and Elashoff 1990).

In addition to gender and mechanization, other factors such as household size, size of cultivated land, number of animals, the use of fertilizer and herbicides may also affect daily time-use. As this paper focuses on farming activities, the influence of such covariates was further studied in univariate models, where the time-use for selected agricultural activities was regressed with different covariates. Hence, multiple linear regressions were performed where all regressors entered the model linearly without interaction. Fixed main effects for community, mechanization, gender, and the interaction between gender and mechanization, as well as random intercepts for households, were constituent components of the model. Covariates were selected based on economic theory and then successively removed from the model by backward-elimination as suggested by Chastin et al. (2015). The criterion for keeping a covariate was a p-value smaller than $10 \%$ in a partial Wald-F-test. All three response variables of the three multiple linear regression models, time spent on land preparation, weeding and harvesting/processing were square-root transformed to fulfill the homogeneity of variance requirement. The multiple linear regressions were fitted using the MIXED procedure.

\section{Results}

Table 3 provides a descriptive overview of time-use for the nine time-use categories by power source used for land preparation (manual labor, animal draught and tractors) and by gender (men, women, boys, and girls). Figure 3 visualizes the time-use differences between household members from farm households with different types of power sources for the land preparation period. In the subsequent sections, the research hypotheses will be tested using compositional data analysis based on model (1). "Are land preparation activities gendered?" section addresses hypotheses 1 and 2, "Is the surplus time associated with mechanization used differently by gender?" section addresses hypothesis 3 and "What happens during the next farming steps?" section focuses on hypothesis 4 .

\section{Are land preparation activities gendered?}

In "Conceptual framework and research hypotheses" section, two hypotheses were developed: (1) land preparation is predominantly a male activity, and (2) the use of mechanization during land preparation is associated with lower workloads for men as compared to women. Concerning the first 


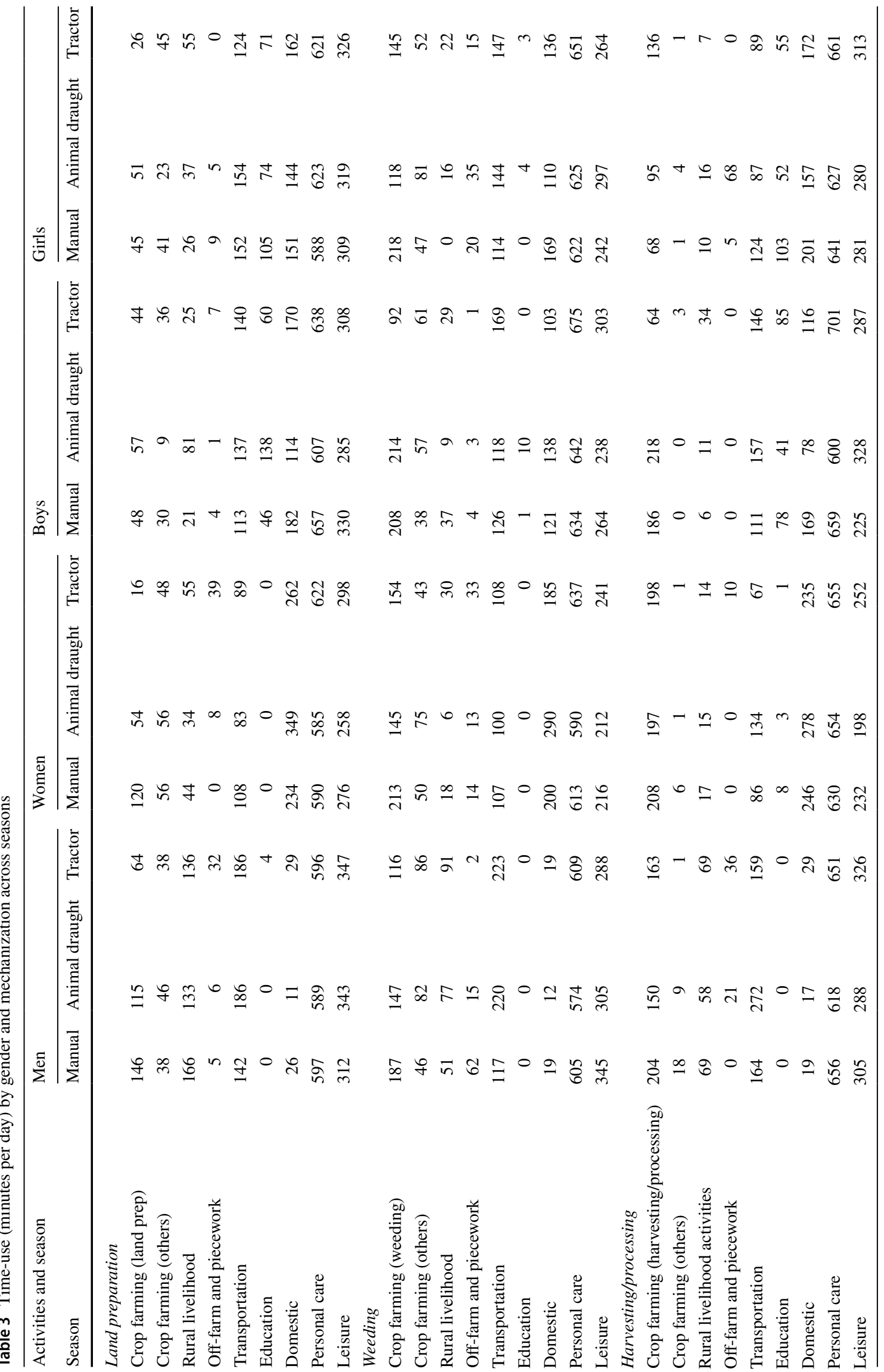


Table 4 Partial Wald-F-tests for fixed effects of model (1) during land preparation

\begin{tabular}{llccrr}
\hline Effect & Description & Numerator DF & $\begin{array}{l}\text { Denominator } \\
\text { DF }\end{array}$ & F-value & p-value \\
\hline$\mu_{k}$ & Time-use category & 8 & 20 & 756.53 & $<0.0001$ \\
$\tau_{k j}$ & Mechanization (M) & 16 & 48 & 1.90 & 0.0450 \\
$\gamma_{k l}$ & Gender (G) & 24 & 72 & 17.29 & $<0.0001$ \\
$(\tau \gamma)_{k j l}$ & Interaction of M and G & 48 & 136 & 1.15 & 0.2597 \\
\hline
\end{tabular}

Tests are based on model (1); $k=1$ to 8 are 8 additive log-ratios of time-use categories with 'personal care' as a common denominator

Denominator Degrees of freedom are adjusted according to the 'between-within-method'

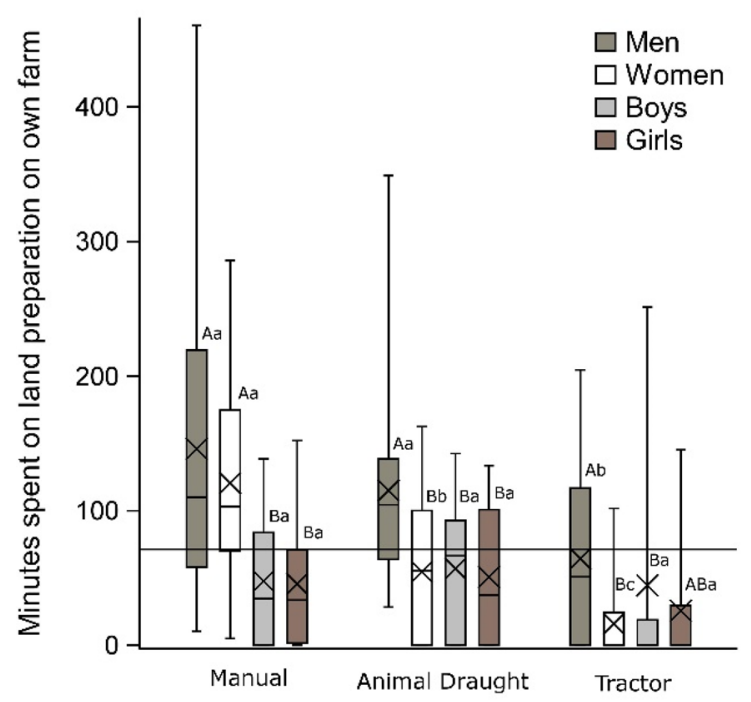

Fig. 4 Boxplots (left) and descriptive log-ratios of geometric means (right) of minutes spent on 'land preparation on the own farm' by mechanization and gender. In the right figure, each bar represents the log-transformed ratio of the mean of each group compared to the overall mean of all 12 groups. Log-ratios larger or lower than zero

hypothesis, F-tests show a significant correlation between time-use, gender, and mechanization based on model (1). The composition of overall time-use differs depending on gender and mechanization (see Table 4).

While there is no significant interaction between mechanization and gender on the overall daily composition of time-use, there is a significant interaction between gender and mechanization $(\mathrm{p}<0.0001)$ for the single time-use activity 'land preparation on the own farm' based on model (1), an association further explored using pairwise t-tests (see Fig. 4).

In tractor-households, men spent significantly less time on land preparation (arithmetic mean of $64 \mathrm{~min}$ ) compared to animal-draught-households ( $115 \mathrm{~min}, \mathrm{p}=0.0072$ ) and manual-households (146 min, $\mathrm{p}=0.0081$ ), the latter two did not differ significantly $(p=0.9671)$. Women in manual-households spent 120 min on land preparation while their counterparts in animal-draught-households (54 $\mathrm{min}, \mathrm{p}=0.0040$ )

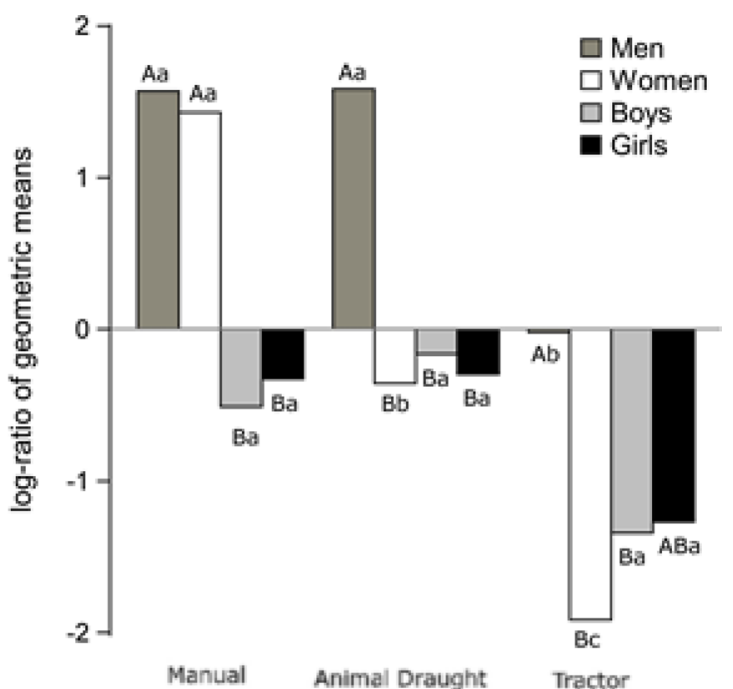

represent above or below average time-use. Pairwise comparisons are based on estimates from model (1). Lower case letters (e.g. $a$, $b)$ refer to differences by mechanization within the same gender at $\alpha$ $=10 \%$. Capital letters (e.g. $A, B$ ) refer to differences of different gender within the same mechanization type at $\alpha=10 \%$

and tractor-households spent significantly less time (16 min, $\mathrm{p}<0.0001)$. Time spent is significantly lower for women in tractor-households compared to animal-draught-households $(\mathrm{p}=0.0063)$. The lower amount of time-use for land preparation can be observed despite tractor- and animal-draughthouseholds cultivating more land (see Table 1). Time spent did not differ significantly between mechanization types for boys and girls. Within tractor and animal-draught-households, men significantly spent the highest amount of time (64 and $115 \mathrm{~min}$ ) compared to women ( $16 \mathrm{~min}, \mathrm{p}=0.0005$ for tractor-households and $54 \mathrm{~min}, \mathrm{p}=0.0011$ for animaldraught-households) and children. However, in manual traction using households the contribution of men (146 min) and women $(120 \mathrm{~min})$ did not differ $(\mathrm{p}=0.8211)$ and both spent significantly more time than their children.

The difference between time-uses may also occur because households differ concerning other variables (and differed already before some became mechanized). In Table 5, some 
Table 5 Multiple linear regression of covariates on time-use for land preparation

\begin{tabular}{llc}
\hline Effect & Estimate & p-value \\
\hline Community & $-^{\mathrm{a}}$ & $\mathbf{0 . 0 1 5}$ \\
Gender (M, F, B, G) & $-^{\mathrm{a}}$ & $<\mathbf{. 0 0 0 1}$ \\
Mechanization & $-^{\mathrm{a}}$ & $\mathbf{0 . 0 0 1}$ \\
Gender*mechanization & $-^{\mathrm{a}}$ & $\mathbf{0 . 0 2 7}$ \\
Off-farm income & $-0.001(0.003)$ & $\mathbf{0 . 0 6 9}$ \\
Costs per ha & $0.000(0.000)$ & 0.122 \\
Pregnancy & $1.230(1.059)$ & 0.259 \\
Household size & $-0.135(0.186)$ & 0.471 \\
Tropical livestock unit & $-0.037(0.062)$ & 0.544 \\
Distance market & $-0.013(0.022)$ & 0.550 \\
Hired labour & $-0.010(0.025)$ & 0.691 \\
Months with food shortage & $0.077(0.244)$ & 0.754 \\
Education & $0.024(0.107)$ & 0.833 \\
Crop diversity & $0.068(0.398)$ & 0.865 \\
Land cultivated & $-0.009(0.118)$ & 0.933 \\
\hline
\end{tabular}

Multiple linear regression on square-root transformed time spent in land preparation. Covariates were chosen based on economic theory and removed in back-wards elimination. The threshold of deletion was a p-value below $10 \%$. The model contains a random intercept for each household; Parameter estimates for slopes and standard error in parentheses

a Parameter estimates for qualitative factors are not shown for brevity Bolded p-values are signifcant at the $10 \%$ level

factors that might also be correlated with time spent on land preparation are controlled for using a multiple linear regression. Controlling these factors, the interaction factor (gender*mechanization) remains significant. This suggests that mechanization has more influence on the time spent than factors such as cultivated land size, household size, or hired labor. However, many of these variables differ between the mechanization groups (Table 1) and, consequently, a regression on these variables without mechanization shows significant slopes (for example, a negative slope for cultivated land size, data not shown).

The hypothesis that land preparation is a male activity can only partially be confirmed. In manual-households, men and women equally contribute to land preparation. Gender differentiation is only associated with different forms of mechanization (the use of animal draught and tractors). In animal-draught-households, women spend less time on land preparation activities compared to manual-households, while men spent a comparable amount of time. When using tractors, both men and women work less but men work more than women. In general, the time spent on land preparation is the lowest for all household members when tractors are used and children contribute less time irrespective of mechanization. The hypothesis that the use of mechanization during land preparation is associated with lower workloads for men as compared to women cannot be confirmed.

\section{Is the surplus time associated with mechanization used differently by gender?}

The previous section has shown that agricultural mechanization is associated with less time spent on land preparation. In this section, the hypothesis that the surplus time available in mechanized households is used differently by gender is tested. In the previous section, no surplus time for children associated with mechanization was found, and they are therefore omitted from this section.

Estimates of time spent on different activities from model (1) were compared in pairwise $t$ tests between men
Table 6 Differences in time-use relative to manual-households by mechanization and gender

\begin{tabular}{|c|c|c|c|c|}
\hline & \multicolumn{2}{|c|}{ Animal draught } & \multicolumn{2}{|l|}{ Tractor } \\
\hline & Women & Men & Women & Men \\
\hline Crop farming (land preparation) & $-65^{\mathrm{a}}(0.004)$ & $-31^{\mathrm{a}}(0.967)$ & $-105^{\mathrm{b}}(<0.0001)$ & $-81^{\mathrm{b}}(0.008)$ \\
\hline Crop farming (others) & $0^{\mathrm{a}}(0.453)$ & $8(0.129)$ & $-8^{\mathrm{b}}(0.094)$ & $-1(0.617)$ \\
\hline Rural livelihood activities & $-10(0.757)$ & $-33(0.631)$ & $10(0.779)$ & $-30(0.899)$ \\
\hline Off-farm and seasonal labour & $8^{\mathrm{a}}(0.399)$ & $1(0.747)$ & $39^{\mathrm{b}}(0.087)$ & $27(0.664)$ \\
\hline Transportation & $-24(0.677)$ & $43(0.398)$ & $-19(0.254)$ & $43(0.562)$ \\
\hline Education & $0(0.983)$ & $0(0.893)$ & $0(0.923)$ & $4(0.534)$ \\
\hline Domestic & $114(0.123)$ & $-15^{\mathrm{a}}(0.553)$ & $28(0.409)$ & $3^{\mathrm{b}}(0.131)$ \\
\hline Leisure & $-18(0.613)$ & $31(0.216)$ & $22(0.828)$ & $35(0.473)$ \\
\hline
\end{tabular}

Lower case letters (e.g. a, b) show significant differences between the three groups based on pairwise t-tests at $\alpha=10 \%$. p-values from comparisons with manual-households are reported in parentheses. For example, for the activity 'crop farming (others)', women in animal-draught-households spent the same, and women in tractor-households spent 8 min less time compared to manual-households. While the first difference is statistically not significant $(\mathrm{p}=0.453)$, the second is at $\alpha=10 \%$. Pairwise comparison between the time-use of women in animal- and tractor-households was significant at $\alpha=10 \%$, therefore the two values carry different lower case letters $a$ and $b$ 


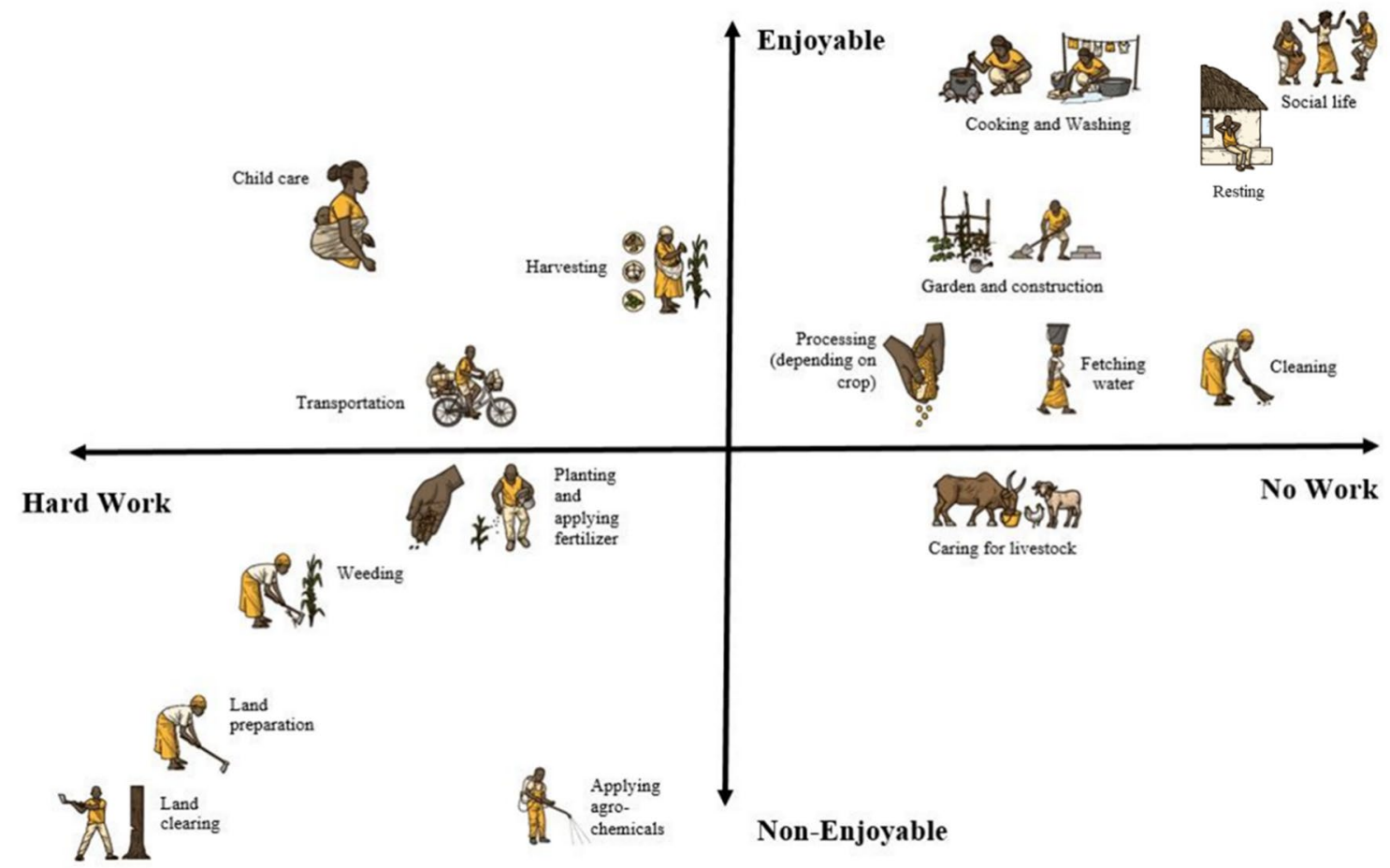

Fig. 5 Matrix of activities by enjoyableness and drudgery. Source: Authors, based on focus group discussions

and women and between the three mechanization categories. Table 6 presents the difference compared to manualhouseholds. Table 6 suggests that women in animal-draughthouseholds spent significantly less time $(65 \mathrm{~min})$ on land preparation compared to manual-households. This was not the case for men who thus have no extra time that could be spent on other activities. It is not clear for which activities the additional time that women in animal-draught-households have is used. Potentially, time is spent on domestic work, which is 114 min higher but the difference is slightly above significance.

In tractor-households, both men and women spent less time on land preparation activities compared to manualhouseholds. The extra time seems to be used for off-farm work and seasonal labour by women. Off-farm work comprised of work as tailors, hairdressers, saleswomen, clinic helpers, and kindergarten teachers and allowed women to earn 10-20 Zambian Kwacha (or around 1-2 Euros) per day. Some women worked as teachers and earned significantly more. The women working as seasonal workers earned around 10-15 Kwacha (1-1.5 Euros) daily, however, this type of work was constrained to a few weeks per annum.

Men in tractor-households spent more time on domestic work compared to animal-draught-households but this is compared to a low base, and compared to manual-households, no significant difference was found. This suggests that the surplus time may be used across all other time-use categories such as leisure and transport, and therefore, stays below the detection level. Still, the hypothesis that males and females in mechanized households use their extra time differently can be confirmed.

Figure 5 presents a framework of how different activities are perceived by the participants of the focus group discussions (see "Data collection methods and sampling" section). Following this framework, animal-draught- and tractorhouseholds spent less time on hard and non-enjoyable activities but more on enjoyable activities (such as child care, cleaning, and cooking). Figure 5 shows a stylized framework from both male and female focus group discussions as, interestingly, there were no major gender differences on the activity perceptions, in particular participants placed most of the activity stickers in the same quadrants of the framework in all focus group discussions. While the location of activities within the quadrant differed, these differences cannot be captured due to the qualitative nature of discussions. Thus, despite not finding a significant difference concerning time spent on leisure, respondents seem to have a higher life quality concerning these criteria.

\section{What happens during the next farming steps?}

In this section, the hypothesis is tested whether females spent more time on weeding and harvesting/processing on 
Table 7 Partial Wald-F-tests for fixed effects of model (1) at weeding and harvesting and processing

\begin{tabular}{llccrr}
\hline Effect & Description & Numerator DF & $\begin{array}{l}\text { Denominator } \\
\text { DF }\end{array}$ & F-value & p-value \\
\hline$\mu_{k}$ & Time-use category & 8 & 20 & 1313.09 & $<0.0001$ \\
$\tau_{k j}$ & Mechanization (M) & 16 & 48 & 2.09 & 0.0249 \\
$\gamma_{k l}$ & Gender (G) & 24 & 72 & 83.82 & $<0.0001$ \\
$(\tau \gamma)_{k j l}$ & Interaction of M and G & 48 & 128 & 2.53 & $<0.0001$ \\
\hline
\end{tabular}

Tests are based on model (1); $k=1$ to 8 are 8 additive log-ratios of time-use categories with 'personal care' as a common denominator

Denominator Degrees of freedom are adjusted according to the 'between-within-method'

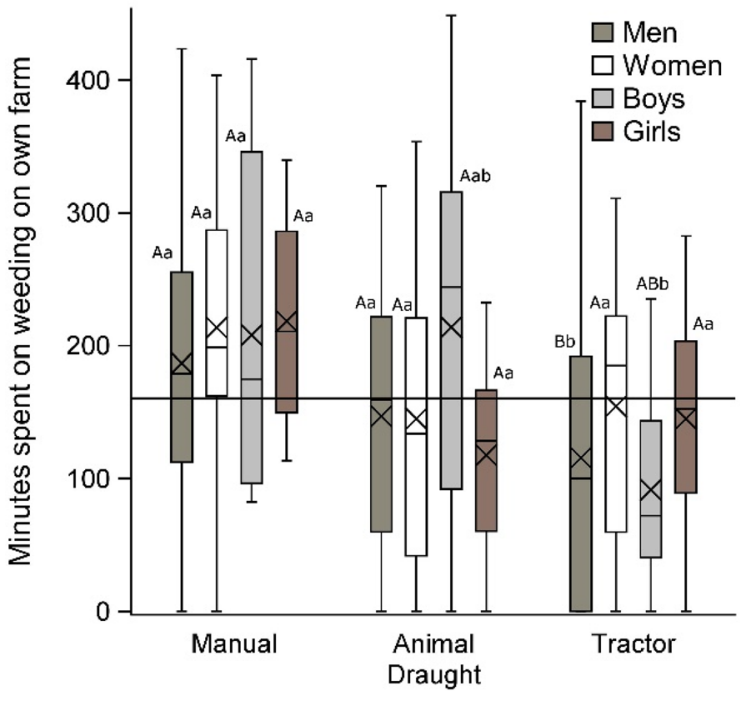

Fig. 6 Boxplots (left) and descriptive log-ratios of geometric means (right) of time-use on weeding on own farm by mechanization and gender. In the right figure, each bar represents the log-transformed ratio of the mean of each group compared to the overall mean of all 12 groups. Log-ratios larger or lower than zero represent above or

mechanized farms compared to non-mechanized farms. This could be the case when mechanized households cultivate more land, which increases the need for weeding and harvesting/processing, which might be primarily female tasks. The argument that mechanization leads to land expansion cannot be thoroughly analyzed in this study as it is based on cross-sectional data but seems plausible based on economic theory and previous studies (see for example Adu-Baffour et al. 2019, for Zambia).

The sampled tractor-households cultivated significantly $(\mathrm{p}=0.0053)$ more land (6.7 ha) than animal-draught-households (3.9 ha), and animal-draught-households cultivated significantly more land than manual-household (2.1 ha). The larger amount of land cultivated may be correlated with more time spent on weeding (and harvesting/processing). Indeed, Table 7 suggests a significant effect of the interaction of mechanization and gender on the daily time-use composition during weeding based on model (1).

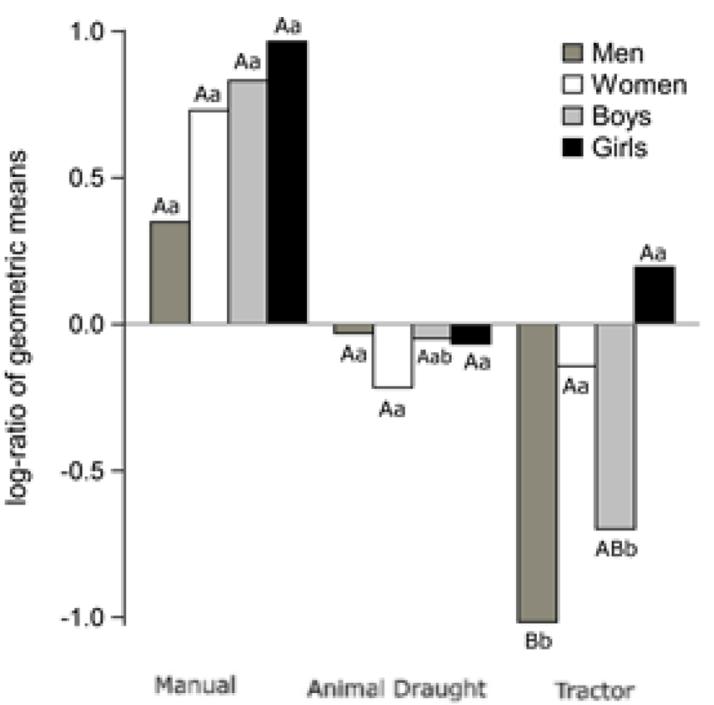

below average time-use. Pairwise comparisons are based on estimates from model (1). Lower case letters (e.g. $a, b)$ refer to differences by mechanization within the same gender at $\alpha=10 \%$. Capital letters (e.g. $A, B)$ refer to differences between different genders within the same mechanization type at $\alpha=10 \%$

However, there are no significant gender differences in pairwise $t$ tests at $\alpha=10 \%$ between manual-households and animal-draught-households for the single time-use category of 'weeding on the own farm' (Fig. 6). In tractor-households, men work significantly less than women, and men and boys work significantly less compared to their counterparts in the manual- and animal-draught-households. This suggests that gender differentiation for weeding activities is only associated with the use of tractors. However, girls and women still spend less time on weeding as compared to non-mechanized households.

Despite cultivating more land, animal-draught- and tractor-households do not spend more time on weeding. The time spent on weeding was highest for manual-households (204 min), significantly higher than animal-draughthouseholds (152 min, $\mathrm{p}=0.075)$. Time spent on weeding for animal-draught-households did not differ significantly from tractor-households (130 min, $\mathrm{p}=0.308$ ). However, time 


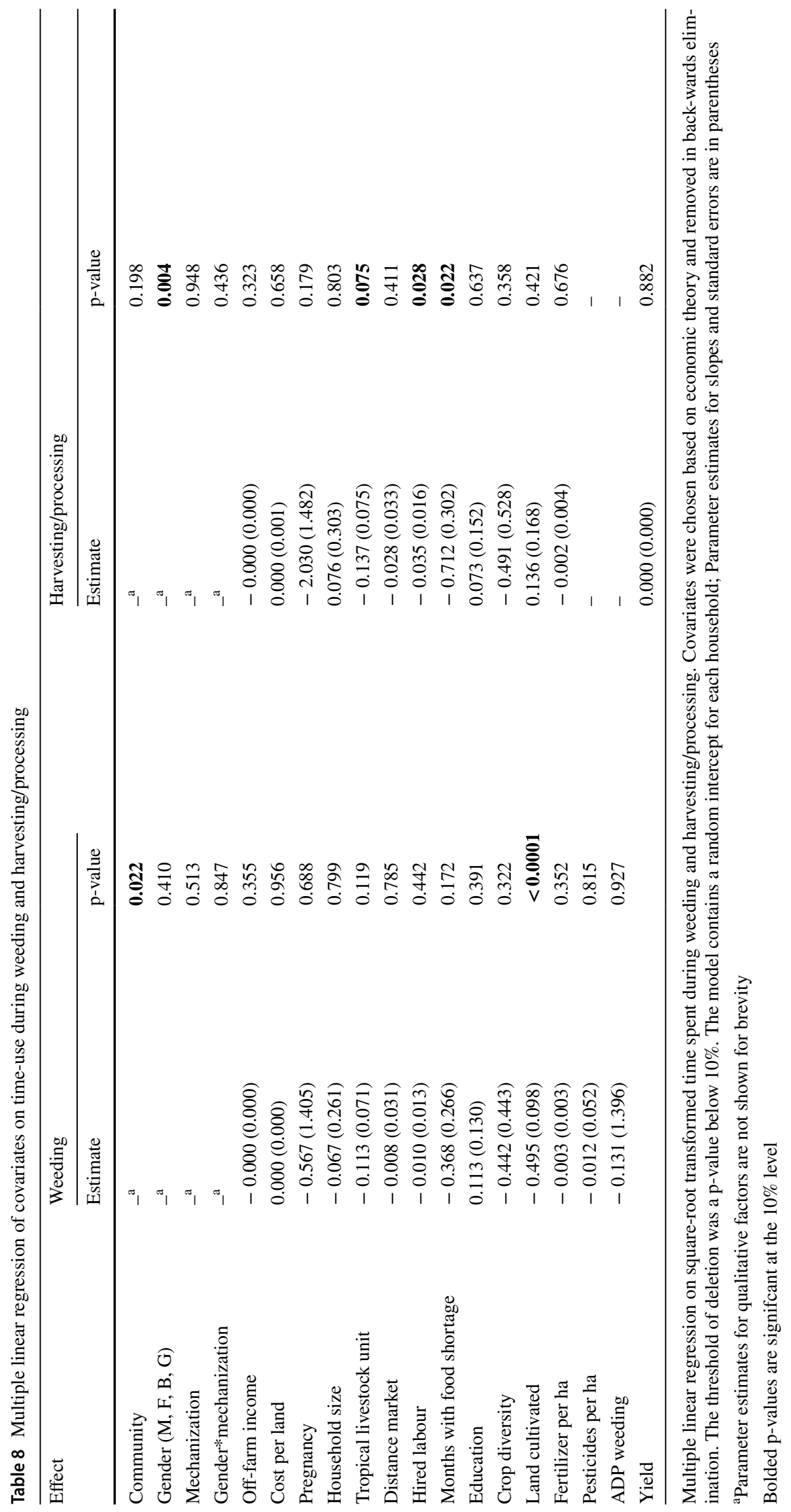


spent on weeding may also be influenced by other factors such as the use of herbicides and laborers.

Table 8 shows that when controlling for covariates, the correlation between mechanization and time spent on weeding becomes insignificant as the size of cultivated land is more strongly correlated with weeding. The relationship between cultivated land size and time-use for weeding is negative. For subsistence farming households with little land, weed control may be more essential than for households with large landholdings. Thus, the hypothesis that mechanization of land preparation is associated with increased female labor for weeding cannot be confirmed.

However, this may still be the case for harvesting/ processing. Table 9 shows that there were no tuc-specific effects of mechanization and the interaction of mechanization and gender on the overall daily time-use composition during harvesting/processing.

In pairwise t-tests on the single time-use category of harvesting/processing, no gender differences were found in manual-households based on model (1). In animal-draughthouseholds, girls work significantly less than all other household members, while boys work less in tractor-households (see Fig. 7).

Table 8 shows that factors other than mechanized land preparation have a bigger influence on time spent on harvesting/processing. This includes livestock owned based on tropical livestock units - potentially, households with more livestock spend more time caring for animals and have less time for harvesting/processing. Another factor is the use of hired labor: households hiring more labor spent less time on harvesting/processing. Finally, households with more months of food shortage spent less time on harvesting/processing (even after yields were dropped from the regression), a phenomenon that may show that households that suffered food shortages consume most of the harvest directly rather than processing for sale. It may also be that such households have less energy to work.

The hypothesis that agricultural mechanization during land preparation increases female labor needed for harvesting/processing cannot be confirmed. However, post-harvest technologies themselves are likely to have important gender implications regarding time-use.

\section{Discussion and conclusion}

New technologies, policies, and practices can affect the intra-household allocation of time in smallholder farming households, which may put more vulnerable household members at a disadvantage. Understanding time-use effects is important to target policy interventions. However, exploring such effects has been difficult because (1) a lack of suitable data collection methods to collect detailed and reliable data on time-use, including from illiterate respondents and children and (2) the structure of time-use data, which cannot be addressed with conventional statistical methods. This study showed that using a pictorial smartphone application called Timetracker provides accurate and comprehensive data to study such concerns. Furthermore, the study has shown that compositional data analysis can be used to address the specific challenges of time-use data. Solving these two challenges, the study then explored timeuse patterns associated with different levels of agricultural mechanization.

The study makes a contribution to the literature on timeuse and gender roles in smallholder farming households in developing countries. This study confirms previous literature highlighting strong gender patterns concerning domestic work and child care activities (Arora 2015). However, the study finds that while women do more domestic work than men, boys and girls spend similar amounts of time on such chores. Concerning farming activities, the study shows that some activities are gendered, for example, land preparation, confirming previous studies (Alesina et al. 2013; Baanante et al. 1999). However, when stratifying households by mechanization type, this gender differentiation seems to be associated only with mechanization and cannot be detected for households relying on manual labor. No significant differences between children from differently mechanized households during land preparation were found, which is in contrast to Adu-Baffour et al. (2019), who, having a larger
Table 9 Partial Wald-F-tests for fixed effects of model (1) during harvesting/processing

\begin{tabular}{llccrr}
\hline Effect & Description & Numerator DF & $\begin{array}{l}\text { Denominator } \\
\text { DF }\end{array}$ & F-value & p-value \\
\hline$\mu_{k}$ & Time-use category & 8 & 20 & 1659.88 & $<0.0001$ \\
$\tau_{k j}$ & Mechanization (M) & 16 & 48 & 0.46 & 0.9560 \\
$\gamma_{k l}$ & Gender (G) & 24 & 72 & 14.88 & $<0.0001$ \\
$(\tau \gamma)_{k j l}$ & Interaction of M and G & 48 & 136 & 1.18 & 0.2251 \\
\hline
\end{tabular}

Tests are based on model (1); $k=1$ to 8 are 8 additive log-ratios of time-use categories with 'personal care' as a common denominator

Denominator Degrees of freedom are adjusted according to the 'between-within-method' 


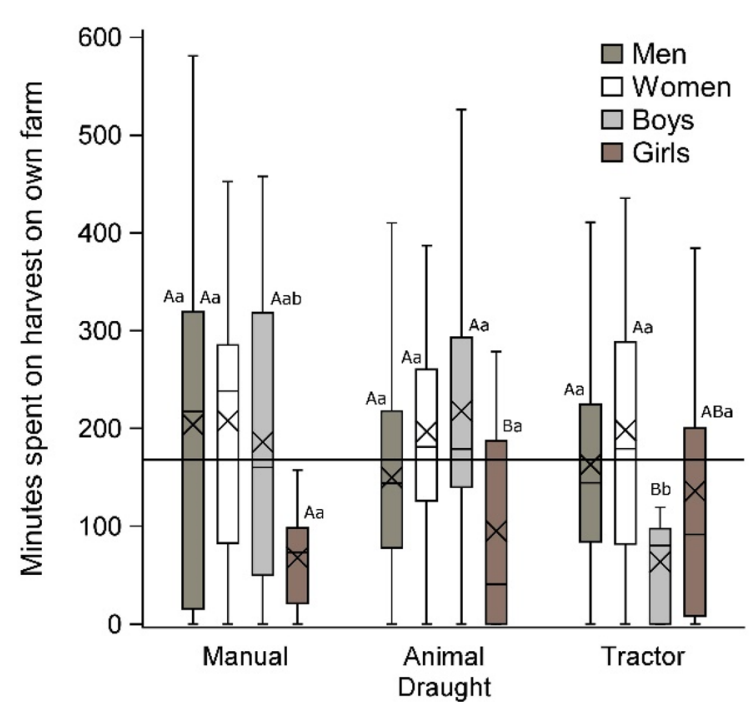

Fig. 7 Boxplots (left) and descriptive log-ratios of geometric means (right) of time-use on harvesting/processing on own farm by mechanization and gender. In the right figure, each bar represents the logtransformed ratio of the mean of each group compared to the overall mean of all 12 groups. Log-ratios larger or lower than zero represent

sample and focusing on the whole of Zambia, found that children benefit from agricultural mechanization. No clear gender patterns were found for weeding and harvesting.

These results echoes findings from Doss (2001) and Palacios-Lopez et al. (2017) who question stylized facts on the gender division in agriculture. The results suggest that agricultural transformation, such as the adoption of agricultural mechanization, changes gender patterns. As outlined above, land preparation seems to be a male-dominated activity only in mechanized households. This is an important finding because women's work in land preparation-a task associated with hard work and high energy costs (see also Fig. 6) - is often overlooked. It remains unclear whether this is a sign of empowerment or dis-empowerment as when women become less involved in field preparation they may potentially have less claim to the benefits, an aspect that future studies should explore.

The surplus of time associated with mechanization seems to be used for various activities. There is some (weak) evidence that women in animal-draught using households spent more time on domestic chores compared to manual labor using households, which may be a sign of disempowerment. In tractor-using households, the extra time associated with mechanization seems to be used for off-farm work by women and domestic work such as household chores and care for children by men, which may be a sign of empowerment in women. Combining the difference in time-use with the qualitative data on which activities are perceived as more enjoyable and less hard work suggests that animal-draught- and tractor

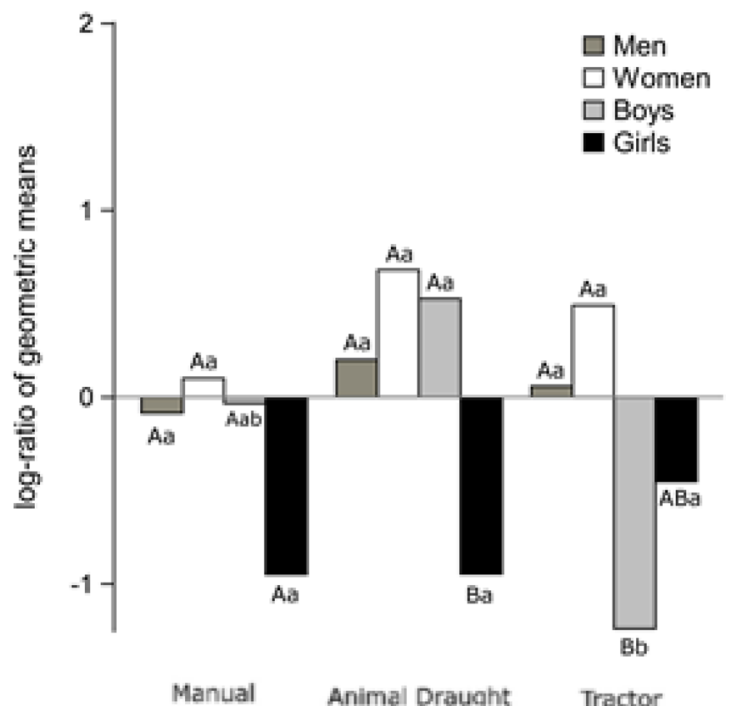

above or below average time-use. Pairwise comparisons are based on estimates from model (1). Lower case letter (e.g. $a, b$ ) refer to differences by mechanization within the same gender at $\alpha=10 \%$. Capital letters (e.g. $A, B$ ) refer to differences of different gender within the same mechanization type at $\alpha=10 \%$

using households spent more time on activities that are enjoyable and less hard work such as child care, cleaning, and cooking.

However, additional qualitative data on perceptions on time-use, social norms related to time-use, agency over time-use, and the mechanisms explaining how time-use can be re-negotiated is needed to better interpret the observed time-use changes (see also Seymour et al. 2020). For example, while the above-mentioned observation that women in animal-draught using households spent more time on domestic chores may indicate disempowerment, it may also signal an increase in wellbeing (and perhaps even empowerment) if the women have more time to complete the same amount of domestic chores and can reduce the amount of stressful synchronous activities (Seymour et al. 2020). Similarly, spending more time on off-farm work may not signal empowerment when women have no agency over their labor or control over the extra revenue.

As outlined in the conceptual framework, new technologies can also change time-use through second-round effects-via changes in farm production. For mechanization, there is a concern that mechanization leads to farmland expansion and a higher workload associated with weeding and harvesting, tasks often performed by women and children. The results suggest that mechanization is not associated with a higher workload during weeding and harvesting/processing, despite mechanized households cultivating more land. A reason might be that mechanized land preparation can reduce weed pressure (Nyamangara et al. 2014). This confirms Baudron et al. (2019) who, using qualitative 
techniques, found that mechanized land preparation reduces the need for weeding and thus women's drudgery. Also, households with more land spent less time on weeding as the intensity of labor use may decrease with farm size (Sen 1962; Wineman and Jayne 2018).

As mentioned above, the study faces some limitations. Given that the focus has been on finding a reliable way to collect time-use data and how to analyze such data, the sample remained small. In subsequent studies, larger sample sizes should be used. Ideally, future studies can use a randomized control trial approach to establish causality. Another limitation is that the extrapolation of the daily data to the entire farm season remains difficult (Daum et al. 2019). Also, as outlined above time-use is only one aspect that determines the well-being of household members, and other pathways relating mechanization and wellbeing such as control over income and nutrition should be analyzed by future studies (Eerdewijk and Danielsen 2015).

Lastly, it is important to keep in mind that, while we find no negative association of agricultural mechanization on women's and children's time allocation, this may be different in other situations depending on the tasks and crops that are mechanized, on existing gender roles, and how they can be re-negotiated (Doss 2013; Fisher et al. 2000) as well the use of complementary inputs. As shown above, households that use mechanization may also apply other household-labor-saving methods in their production process, especially hired labor and pesticides. In this study, these factors did not differ significantly across the three groups of mechanization, which may be due to the small sample size, however.

Future studies may go beyond looking at the amount of time spent on different activities, which neglects the fact that certain activities may be more tiresome than others. Understanding such aspects would be important as mechanization may reduce the intensity of labor for particular activities while not necessarily changing the duration of this activity. In future studies, the Timetracker application may use pop-up windows asking participants about the well-being associated with ongoing activities. This would allow seeing the distribution of time-spent on enjoyable/non-enjoyable and hard/easy activities by gender. Similarly, questions on the agency over time-use may be asked. Such an approach is not without limitations, as perceptions and agency may be subjective and socially constructed, but may nevertheless provide a more nuanced understanding of time-use.

The study has shown that pictorial smartphone applications can help to collect "difficult-to-recall" data such as data on time-use from different members of households in developing countries where literacy levels can be low. The study opens the field to more studies focusing on (rural) development and the allocation of time-use within households.
For example, this study found a high share of time spent on mobility and transportation, which is often neglected by studies focusing on time-use in agriculture, although reducing such time-use may allow farmers to spend more time on their fields. Similarly, the time-use effects of technologies for home economics such as improved cookstoves, electronic household items, and processed food, which may all help to reduce time poverty among women, and loosen constraints to participate in paid work, are interesting to study. Overall, the study has shown that there is an untapped potential to use pictorial smartphone applications for the collection of data. Such data can help to explore the drivers and effects of technology adoption, to reveal gender asymmetries, and to avoid adverse effects on more vulnerable population groups, such as women and children when designing development interventions and policies.

Acknowledgements We are grateful to all the farm families participating in the study and the financial support from the "Program of Accompanying Research for Agricultural Innovation" (PARI), which is funded by the German Federal Ministry of Economic Cooperation and Development (BMZ).

Funding Open Access funding enabled and organized by Projekt DEAL.

\section{Compliance with ethical standards}

Conflict of interest The authors declared that they have no conflict of interest.

Ethical standards The study was conducted according to the guidelines laid down in the Declaration of Helsinki and approved by the Ethics committee of the University of Hohenheim. All study participants gave their written consent to participate in the study. For study participants below the age of 18, consent was obtained from themselves and their parents or guardians.

Open Access This article is licensed under a Creative Commons Attribution 4.0 International License, which permits use, sharing, adaptation, distribution and reproduction in any medium or format, as long as you give appropriate credit to the original author(s) and the source, provide a link to the Creative Commons licence, and indicate if changes were made. The images or other third party material in this article are included in the article's Creative Commons licence, unless indicated otherwise in a credit line to the material. If material is not included in the article's Creative Commons licence and your intended use is not permitted by statutory regulation or exceeds the permitted use, you will need to obtain permission directly from the copyright holder. To view a copy of this licence, visit http://creativecommons.org/licenses/by/4.0/.

\section{References}

Adu-Baffour, F., T. Daum, and R. Birner. 2019. Can small farms benefit from big companies' initiatives to promote mechanization in Africa? A case study from Zambia. Food Policy 84: 133-145. 
Agarwal, B. 1981. Agricultural mechanisation and labour use: A disaggregated approach. International Labour Review 120 (1): $115-127$

Aitchison, J. 1982. The statistical analysis of compositional data. Journal of the Royal Statistical Society: Series B (Methodological) 44 (2): 139-160.

Alesina, A., P. Giuliano, and N. Nunn. 2013. On the origins of gender roles: Women and the plough. The Quarterly Journal of Economics 128 (2): 469-530.

Arora, D. 2015. Gender differences in time-poverty in rural Mozambique. Review of Social Economy 73 (2): 196-221.

Arthi, V., K. Beegle, J. De Weerdt, and A. Palacios-López. 2018. Not your average job: Measuring farm labor in Tanzania. Journal of Development Economics 130: 160-172.

Baanante, C., T.P. Thompson, and K. Acheampong. 1999. Labour contributions of women to crop production activities in three regions of West Africa: An analysis of farm-survey data. Research Review of the Institute of African Studies 15 (1): 80-100.

Bacon-Shone, J. 2011. A short history of compositional data analysis. In Compositional data analysis: Theory and applications, ed. V. Pawlowsky-Glahn and A. Buccianti, 3-11. Hoboken: Wiley.

Baudron, F., M. Misiko, B. Getnet, R. Nazare, J. Sariah, and P. Kaumbutho. 2019. A farm-level assessment of labor and mechanization in Eastern and Southern Africa. Agronomy for Sustainable Development 39 (2): 17.

Ball, J.A. 2020. Women farmers in developed countries: A literature review. Agriculture and Human Values 37 (1): 147-160.

Bell, A., et al. 2019. Assessing recall bias and measurement error in high-frequency social data collection for human-environment research. Population and Environment 40 (3): 325-345.

Benin, S. 2015. Impact of Ghana's agricultural mechanization services center program. Agricultural Economics 46 (S1): 103-117.

Bergman Lodin, J., S. Paulson, and M.S. Mugenyi. 2012. New seeds, gender norms and labor dynamics in Hoima District, Uganda. Journal of Eastern African Studies 6 (3): 405-422.

Beuchelt, T.D., and L. Badstue. 2013. Gender, nutrition-and climatesmart food production: Opportunities and trade-offs. Food Security 5 (5): 709-721.

Binswanger, H. 1986. Agricultural mechanization: A comparative historical perspective. The World Bank Research Observer 1 (1): 27-56.

Bryceson, D.F. 2019. Gender and generational patterns of African deagrarianization: Evolving labour and land allocation in smallholder peasant household farming, 1980-2015. World Development 113: 60-72.

Carletto, C., D. Jolliffe, and R. Banerjee. 2015a. From tragedy to renaissance: improving agricultural data for better policies. The Journal of Development Studies 51 (2): 133-148.

Carletto, C., S. Gourlay, and P. Winters. 2015b. From guesstimates to GPStimates: Land area measurement and implications for agricultural analysis. Journal of African Economies 24 (5): $593-628$

Chastin, S., et al. 2015. Combined effects of time spent in physical activity, sedentary behaviors and sleep on obesity and cardiometabolic health markers: A novel compositional data analysis approach. PLoS ONE 10 (10): e0139984.

Daum, T., and R. Birner. 2017. The neglected governance challenges of agricultural mechanisation in Africa-insights from Ghana. Food Security 9 (5): 959-979.

Daum, T, and R. Birner. 2020. Agricultural mechanization in Africa: Myths, realities and an emerging research agenda. Global Food Security 26.

Daum, T., et al. 2018. Smartphone apps as a new method to collect data on smallholder farming systems in the digital age: A case study from Zambia. Computers and Electronics in Agriculture 153: $144-150$.
Daum, T., et al. 2019. Times have changed: Using a pictorial smartphone app to collect time-use data in rural Zambia. Field Methods 31 (1): 3-22.

Diao, X., et al. 2014. Mechanization in Ghana: Emerging demand, and the search for alternative supply models. Food Policy 48: $168-181$.

Doss, C. 2001. Designing agricultural technology for African women farmers: Lessons from 25 years of experience. World Development 29 (12): 2075-2092.

Doss, C. 2013. Intrahousehold bargaining and resource allocation in developing countries. The World Bank Research Observer 28 (1): 52-78.

Evers, B., and B. Walters. 2001. The model of a gender-segregated low-income economy reconsidered: Evidence from Uganda. Review of Development Economics 5 (1): 76-88.

Farnworth, C.R., et al. 2016. Gender and conservation agriculture in East and Southern Africa: Towards a research agenda. International Journal of Agricultural Sustainability 14 (2): 142-165.

Fischer, G., et al. 2018. Gender and mechanization: Exploring the sustainability of mechanized forage chopping in Tanzania. Journal of Rural Studies 64: 112-122.

Fisher, M.G., R.L. Warner, and W.A. Masters. 2000. Gender and agricultural change: Crop-livestock integration in Senegal. Society \& Natural Resources 13 (3): 203-222.

Fraval, S., et al. 2019. Making the most of imperfect data: A critical evaluation of standard information collected in farm household surveys. Experimental Agriculture 55 (2): 230-250.

Garcia, A.S., and T. Wanner. 2017. Gender inequality and food security: Lessons from the gender-responsive work of the International Food Policy Research Institute and the Bill and Melinda Gates Foundation. Food Security 9 (5): 1091-1103.

Gupta, N., et al. 2018. A comparison of standard and compositional data analysis in studies addressing group differences in sedentary behavior and physical activity. International Journal of Behavioral Nutrition and Physical Activity 15 (1): 53.

IAPRI Indaba Agricultural Policy Research Institute. 2016. Rural Agricultural Livelihoods Survey 2015 Survey Report.

ILO International Labor Organization. 2020. Child labor in agriculture. https://www.ilo.org/ipec/areas/Agriculture/lang--en/index .html Accessed March 192020.

Jayne, T.S., et al. 2016. Africa's changing farm size distribution patterns: The rise of medium-scale farms. Agricultural Economics 47 (S1): 197-214.

Johnston, D., et al. 2018. Time use as an explanation for the agri-nutrition disconnect: Evidence from rural areas in low and middleincome countries. Food Policy 76: 8-18.

Kansanga, M., et al. 2019. Traditional agriculture in transition: Examining the impacts of agricultural modernization on smallholder farming in Ghana under the new Green Revolution. International Journal of Sustainable Development \& World Ecology 26 (1): $11-24$.

Kenward, M. G., and J. H. Roger. 1997. Small sample inference for fixed effects from restricted maximum likelihood. Biometrics: 983-997.

Kirui, O. 2019. The Agricultural mechanization in Africa: micro-level analysis of state drivers and effects. ZEF-Discussion Papers on Development Policy 272

Kozak, M., and H.P. Piepho. 2018. What's normal anyway? Residual plots are more telling than significance tests when checking ANOVA assumptions. Journal of Agronomy and Crop Science 204 (1): 86-98.

Kumar, S.K. 1995. Adoption of hybrid maize in Zambia: Effects on gender roles, food consumption, and nutrition. Food and Nutrition Bulletin 16 (3): 1-3. 
Lambrecht, I., et al. 2018. Changing gender roles in agriculture? Evidence from 20 years of data in Ghana. Agricultural Economics 49 (6): 691-710.

Lamidi, E.O. 2019. Household composition and experiences of food insecurity in Nigeria: The role of social capital, education, and time use. Food Security 11 (1): 201-218.

Lobell, D.B., G. Azzari, M. Burke, S. Gourlay, Z. Jin, T. Kilic, and S. Murray. 2020. Eyes in the sky, boots on the ground: Assessing satellite-and ground-based approaches to crop yield measurement and analysis. American Journal of Agricultural Economics 102 (1): 202-219.

Martín-Fernández, J.A., C. Barceló-Vidal, and V. Pawlowsky-Glahn. 2003. Dealing with zeros and missing values in compositional data sets using nonparametric imputation. Mathematical Geology 35 (3): 253-278.

Mukhopadhyay, M. 1984. Silver shackles: Women and development in India. London: Oxfam.

Nyamangara, J., N. Mashingaidze, E.N. Masvaya, K. Nyengerai, M. Kunzekweguta, R. Tirivavi, and K. Mazvimavi. 2014. Weed growth and labor demand under hand-hoe based reduced tillage in smallholder farmers' fields in Zimbabwe. Agriculture, Ecosystems \& Environment 187: 146-154.

Palacios-Lopez, A., L. Christiaensen, and T. Kilic. 2017. How much of the labor in African agriculture is provided by women? Food Policy 67: 52-63.

Pearson, K. 1897. Mathematical contributions to the theory of evolution-on a form of spurious correlation which may arise when indices are used in the measurement of organs. Proceedings of the Royal Society of London 60: 359-367.

Quisumbing, A.R., et al. 2014. Gender in agriculture. Netherlands: Springer.

Quisumbing, A.R., et al. 1996. Women: The key to food security. Food and Nutrition Bulletin 17 (1): 1-2.

Schluchter, M.D., and J.T. Elashoff. 1990. Small-sample adjustments to tests with unbalanced repeated measures assuming several covariance structures. Journal of Statistical Computation and Simulation 37 (1-2): 69-87.

Sen, A.K. 1962. An aspect of Indian agriculture. Economic Weekly 14 (4-6): 243-246.

Seymour, G., H. Malapit, and A. Quisumbing. 2020. Measuring time use in developing country agriculture: Evidence from Bangladesh and Uganda. Feminist Economics 26 (3): 169-199.

Takeshima, H., A. Nin-Pratt, and X. Diao. 2013. Mechanization and agricultural technology evolution, agricultural intensification in sub-Saharan Africa: Typology of agricultural mechanization in Nigeria. American Journal of Agricultural Economics 95 (5): $1230-1236$.
Theis, S., et al. 2018. What happens after technology adoption? Gendered aspects of small-scale irrigation technologies in Ethiopia, Ghana, and Tanzania. Agriculture and Human Values 35 (3): 671-684.

Van Eerdewijk, A., and K. Danielsen. 2015. Gender matters in farm power. Amsterdam: KIT.

Wang, X., F. Yamauchi, and J. Huang. 2016. Rising wages, mechanization, and the substitution between capital and labor: Evidence from small scale farm system in China. Agricultural Rconomics 47 (3): 309-317.

Wineman, A., and T.S. Jayne. 2018. Factor market activity and the inverse farm size-productivity relationship in Tanzania, 79. Research Paper: Feed the Future Innovation Lab for Food Security Policy.

Wodon, Q., and C.M. Blackden. 2006. Gender, time use, and poverty in sub-Saharan Africa. Washington: The World Bank.

Zanello, G., C.S. Srinivasan, and P. Nkegbe. 2017. Piloting the use of accelerometry devices to capture energy expenditure in agricultural and rural livelihoods: Protocols and findings from northern Ghana. Development Engineering 2: 114-131.

Publisher's Note Springer Nature remains neutral with regard to jurisdictional claims in published maps and institutional affiliations.

Thomas Daum is a researcher at the Institute of Agricultural Science in the Tropics (Hans-Ruthenberg-Institute). His work focuses on finding solutions for sustainable agricultural development and food and nutrition security in Africa and Asia. His areas of interest include agricultural mechanization, digital agriculture, youth aspirations, and intra-household dynamics. He is working as a freelance journalist for the Frankfurter Allgemeine Zeitung and Süddeutsche Zeitung, among others.

Filippo Capezzone has been working at the Biostatistics Unit of the Institute of Crop Science at the University of Hohenheim. Currently, he is working as an assistant head of the office at the Rosa-LuxemburgStiftung, Baden Württemberg.

Regina Birner is Chair of Social and Institutional Change in Agricultural Development at the University of Hohenheim, Germany. Her research focuses on the political economy of agricultural policy processes and the role of governance and institutions in agricultural development, with a focus on smallholder farming. Regina Birner is a member of the Advisory Council on Agricultural Policy of the German Federal Ministry of Food and Agriculture (BMEL). 